this corneal vascularization may be regarded as a means of supplementing the nutritional supplies of the cornea under stress, but the mechanism whereby this growth, and subsequent dying away, of the vessels is brought about is not known.

\title{
REFERENCES
}

Leach, E. H. (1955). Trans. Ophthal. Soc. U.K. 75, 425.

Lloyd, J. P. F. (1955). Trans. Ophthal. Soc. U.K. 75, 431.

\section{The biochemistry of the eye}

\section{By Antoinette Pirie, Nuffield Laboratory of Ophthalmology, University of Oxford}

The parts of the eye are diverse in embryological origin, in form, in function and in their biochemistry. This paper can only briefly survey a few aspects of ocular biochemistry, particularly those related to nutrition that are not being examined by other contributors to the Symposium.

\section{The cornea}

The cornea has two main and quite separate layers, the epithelium which has an active metabolism and contains the enzymes and coenzymes necessary for glycolysis and for oxidation of glucose through the pentose-phosphate and the citric-acid cycles (Kinoshita \& Masurat, 1959) and the corneal stroma which contains a few cells and consists mainly of criss-crossing layers of collagen fibres embedded in a mucoprotein and mucopolysaccharide matrix.

The cornea is avascular and the oxygen required for respiration of the epithelial cells diffuses into the tissue from the blood vessels of the conjunctiva and from the aqueous humour, from the air when the eye is open or from the vessels of the lids when the eye is closed. If respiration of the epithelial cells is impaired the cornea becomes hydrated and transmission of light is upset. Smelser (1952) and Smelser \& Chen (I 955) showed that if respiration of the corneal epithelium was inhibited by the fitting of a contact lens, the cornea became waterlogged, swollen and less transparent and the lactic-acid content of the tissue doubled within $3 \mathrm{~h}$. But if a bubble of oxygen was trapped between the contact lens and the surface of the cornea these changes did not occur. The epithelial cells must respire to remain healthy and to keep the ionic balance normal in the corneal stroma.

Vascularization of the cornea of the rat occurs when there is deficiency of many separate amino acids, vitamin A or riboflavin. In man vascularization occurs in riboflavin deficiency. Riboflavin is present in corneal epithelium as flavinadenine dinucleotide and presumably functions as a link in metabolic oxidations. The oxygen uptake of the epithelium and the riboflavin content of the cornea are depressed before vascularization begins (Lee \& Hart, 1944; Bessey \& Lowry, 1944). A noticeable feature of the riboflavin-deficient rat is that the eyes sink deep into the head. This effect is due to the degeneration of the lacrimal glands rather than to failure of 
growth of the eyeball. One might say therefore that lack of secretions of the lacrimal glands induces corneal vascularization. But removal of the main gland, the Harderian gland, has no harmful effect (Pirie, 1948-9).

The stimulus to ingrowth of capillaries into the cornea is not known; there are many corneal diseases in man in which the cornea becomes vascularized and in none of these except riboflavin deficiency is riboflavin of value. If the vitamin is given to a riboflavin-deficient person or animal retrogression of the vessels and corneal opacities, with return of comfort and clear vision, is quite rapid; 2 days sees a change, Io days a near cure. Riboflavin deficiency hardly occurs in this country or Europe. It occurred in the Southern states of America before the war (Sydenstricker, Sebrell, Cleckley \& Kruse, 1940), but I understand does so no longer. On the other hand, cases are reported from India, the West Indies and Africa, where malnutrition is still related directly to poverty.

Severe vitamin A deficiency in man and animals causes keratinization of the conjunctival and corneal epithelia, followed by rupture of the cornea. This most dangerous aspect of vitamin A deficiency which leads to blindness is discussed by other contributors to this Symposium (McLaren, I960; Rodger, 1960).

\section{The lens}

The lens cells are derived from the ectoderm of the embryo. A small clump of cells is folded into the optic cup, rounds itself off, becomes enclosed in a hyaline capsule which is impermeable to cells and to protein and exists, for the whole of adult life, suspended equatorially in the eye without blood supply or nerves. There is a single layer of epithelial cells over the front surface of the lens and growth is due to their division. This division pushes the older cells to the equator where they elongate to form the outermost fibres. Throughout life, though at a diminishing rate, cell division and lens growth goes on, the fibres in the central core of the lens becoming more and more compressed. These fibres lose their nuclei, and even the outer fibres although nucleated contain few mitochondria and microsomes. One can therefore imagine the constituents of lens as a whole as being similar to the supernatant fraction of other tissues, the enzymes that one would expect being mainly soluble enzymes, for example those of glycolysis rather than those of the citric-acid cycle or of oxidative phosphorylation. It is only in the single layer of lens epithelium that enzymes present in nuclei, mitochondria or microsomes in other tissues are likely to be active.

About $35 \%$ of the wet weight of the lens is protein. Recently five proteins from rabbit lens have been crystallized (Wood, Massi \& Solomon, 1959). The lens proteins, or one or more of them, are organ- rather than species-specific and lens protein from the human eye is antigenically indistinguishable from that from the rabbit, the cow or the dog. A man or an animal can become immune or sensitized to his own lens protein and, if a sensitized individual has a cataractous lens removed, release of lens protein within the eye may cause an inflammatory intraocular antigenantibody reaction that may cause loss of vision. 
The lens is dependent on the aqueous humour for nourishment and removal of the waste products of its metabolism. Although it is avascular, yet, like the cornea, it is dependent on oxygen supply for maintenance of normality. If a rat is subjected to low oxygen tension its lens becomes opaque. If metabolism of the young excised lens of a rabbit or calf is inhibited by cooling it becomes opaque, such opacities clearing when the lens is rewarmed.

Thus it seems that the lens needs metabolic energy to maintain clarity as well as for growth. In spite of its dependence on oxygen most of this energy is derived from glycolysis, but glucose, supplied by the aqueous humour, is also oxidized by way of the pentose-phosphate cycle, about $90 \%$ of the glucose used being glycolysed and $10 \%$ oxidized directly (Kinoshita \& Wachtl, 1958). The citric-acid cycle is hardly active in the lens (Kinoshita \& Masurat, 1959). Cytochrome plays no part in lens metabolism, except in the epithelial cells where it is present together with cytochrome oxidase.

Derangements of glucose metabolism are apt to cause cataract. Lens opacities occur in young diabetic animals and occasionally in young human diabetics if untreated. Cataracts also occur in rats if they are fed on large amounts of galactose or xylose. Galactose cataract has its counterpart in the cataracts that develop in galactosaemic babies, such babies having an inborn error of metabolism which prevents them from metabolizing galactose. Kalckar \& Maxwell (x958) have found that erythrocytes of galactosaemic infants lack the enzyme uridyl transferase which carries out the reaction

galactose-I-phosphate + uridine diphosphoglucose

$\longrightarrow$ glucose-I-phosphate + uridine diphosphogalactose.

The absence of this enzyme from the lenses of a galactosaemic infant has also been reported by Lerman (I959), and Schwarz \& Golberg (I955) have found that the lens of the galactose-fed rat contains traces of galactose-I-phosphate. Recently van Heyningen (1959) has found that the lenses of galactose-fed rats contain very large amounts (20 $\mathrm{mg} / \mathrm{g}$ wet weight) of dulcitol whereas those of xylose-fed rats contain xylitol and those of rats with alloxan diabetes contain sorbitol. The cataractous lenses from two human diabetics also contained sorbitol. Accumulation of these polyols seems to occur only in the lens, and the derangement of metabolism that leads to their accumulation has yet to be investigated.

\section{The retina}

The retina has a high rate of respiration and of aerobic and anaerobic glycolysis, and the tissue can be irreversibly damaged if metabolism is upset, by either short impairment of blood supply or injection of iodoacetate which inhibits retinal glycolysis (Noell, 1955). The retinal cells contain photolabile pigments and it is chemical change in these pigments that is thought to initiate the nerve impulse from retina to brain. The connexion between vitamin $\mathrm{A}$ and vision was first shown by Holm (1925) 34 years ago when he found that vitamin A-deficient rats were night-blind, and the participation of vitamin $A$ in a visual process was demonstrated by Wald (1935) who found that exposure of the retina to light released measurable amounts 
of the vitamin. Wald also found a yellow intermediate substance, a carotenoid, that he called retinene, and all recent work on the chemistry of the visual pigments stems from Morton's (1944) identification of retinene as vitamin A aldehyde.

The only visual pigment that has been obtained in a reasonably pure state is rhodopsin. This is a light-sensitive red pigment packed in the outer limbs of the rod cells. It seems to be a lipoprotein with vitamin A aldehyde as its chromophore. Up to $40 \%$ of the dry weight of the outer limb of the rod may be rhodopsin which is insoluble in ordinary media and obviously forms a structural element in the cell. It can be extracted into solution with digitonin or bile salts, and such extracts, prepared in the dark, show maximum absorption of light near $500 \mathrm{~m} \mu$, varying slightly from species to species. This is the wavelength to which the human eye is most sensitive and the visibility curve of the eye in dim light is the same as the absorption curve of extracted rhodopsin. This correspondence is the main evidence that rhodopsin is a functional visual pigment of the eye.

When extracted rhodopsin is exposed to strong light it bleaches and free lipid, protein and retinene appear. Retinene is then reduced to vitamin A by enzymes in the retina. Rhodopsin can be reformed in the dark under certain experimental conditions. The retinene and vitamin $\mathrm{A}$ found after bleaching rhodopsin are the alltrans stereoisomers, vitamin A throughout the body being the same. But all-trans retinene will not form rhodopsin when mixed with retinal-rod protein in the dark though the mixed isomers of retinene prepared from fish-liver oils will do so. Hubbard \& Wald (1952-3) have found that rhodopsin contains the II-cis isomer of retinene. Light will isomerize all-trans retinene to give a small amount of the $\mathrm{II}$-cis isomer, and Hubbard (1955-6) has also found a retinene isomerase in retina which does the same, but it appears to be a very sluggish enzyme. Hubbard \& Kropf (I958) have reported that the primary effect of light on rhodopsin in solution is to isomerize the II-cis retinene to the all-trans form without releasing it from the protein. However, the link between the all-trans isomer and the protein is unstable, so that the molecule then breaks down in light or dark to give free all-trans retinene and protein. A question of great interest is the supply of the specific I r-cis retinene to the retinal cells. This isomer is not present in other tissues of the body, and when fed to vitamin A-deficient animals is only about a quarter as active as all-trans vitamin $\mathrm{A}$ in promoting growth (Ames, Swanson \& Harris, 1955).

How far the bleaching process proceeds in the retina in life is not known. The orange intermediates formed by light are unstable in solution but appear to be more stable in the eye. Rushton (1953) and Wald (1954) have found that the living eye contains over $80 \%$ of unchanged rhodopsin even in ordinary daylight but, in spite of this, the sensitivity of the eye has fallen to a low level. Very small changes in rhodopsin concentration cause a great change in sensitivity.

Many fish, particularly those spawning in fresh water, contain a visual pigment, porphyropsin, made of protein combined with the aldehyde of vitamin $A_{2}$, the dehydrovitamin $\mathrm{A}$.

Light-sensitive pigments of cone cells which may be operative at daylight intensity and be sensitive to colour are still largely unknown. The maximum sensitivity of 
the human eye to bright light is at $560 \mathrm{~m} \mu$. Wald, Brown $\&$ Smith (1954-5) have obtained a pigment, iodopsin, from chicken retina, presumably from the cones, which has an absorption maximum of $562 \mathrm{~m} \mu$ and is made of retinene combined with protein.

Rushton (1953, 1956, 1958) has investigated cone pigments in the living human eye. He has got evidence for the presence of two pigments other than rhodopsin: one is sensitive to red light and has absorption maximum at $590 \mathrm{~m} \mu$, and one is sensitive to green light with absorption maximum at $540 \mathrm{~m} \mu$. Normal eyes contain both pigments, perhaps in separate cells, red-blind protanopes have no red-sensitive pigment and green-blind deuteranopes seem to have the two pigments mixed in the same cone cell.

Night-blindness is one of the earliest clinical signs of vitamin A deficiency. The normal retina builds up rhodopsin in darkness or dim light, but the retina of the vitamin A-deficient person fails to do so. This failure of synthesis can be assessed by measuring the dark adaptation curve, the field of vision of the dark adapted eye, or the electroretinogram.

The most comprehensive study of the early stages of vitamin A deficiency in man is the Medical Research Council Report (Hume \& Krebs, 1949). A study of young men and women in Britain kept on a carotene- and vitamin A-free diet showed that it is extremely difficult to produce any clinical signs of vitamin A deficiency in young otherwise well-fed adults. Although their blood vitamin A content fell to about 50 i.u./100 ml plasma, only a few showed loss of retinal sensitivity judged by dark adaptation and none were conscious of any failure of night vision, although some remained on the diet for over 2 years. This remarkable evidence of the adequate nutrition of the young Englishman and the capacity of the liver to store vitamin $A$ is in terrible contrast to the prevalence of vitamin A deficiency in Asia which is discussed by Rodger (1960). For 25 years we have known that simple vitamin $A$ deficiency is the cause of blindness, yet only last year Oomen (1958) could write thus: 'Xerophthalmia has been the most bitter pill for me to swallow during 18 years of doctor's work in Indonesia. The over and over repeated experience of discovering a child, recently blinded, in the arms of the mother; having to tell her that I now could do nothing more to save its eyesight; remembering that I could have done so with a few spoonsful of cod-liver oil some days ago; these things still enter my nightmares .... . What on earth is nutritional science good for, if, even in the atom age, it is not capable to counteract one of the foulest consequences of bad nutrition?'

\section{REFERENCES}

Ames, S. R., Swanson, W. J. \& Harris, P. L. (1955). F. Amer. chem. Soc. 77, 4134. Bessey, O. A. \& Lowry, O. H. (1944). F. biol. Chem. 155, 635.

Holm, E. (1925). Amer. F. Physiol. 73, 79.

Hubbard, R. (1955-6). भ. gen. Physiol. 39, 935 .

Hubbard, R. \& Kropf, A. (1958). Proc. nat. Acad. Sci., Wash., 44, 130.

Hubbard, R. \& Wald, G. (1952-3). F. gen. Physiol. 36, 269.

Hume, E. M. \& Krebs, H. A. (1949). Spec. Rep. Ser. med. Res. Coun., Lond., no. 264.

Kalckar, H. M. \& Maxwell, E. S. (1958). Physiol. Rev. 38, 77.

Kinoshita, J. H. \& Masurat, T. (1959). Amer. F. Ophthal. 48, no. I, part 2, p. 47. 
Kinoshita, J. H. \& Wachtl, C. (r958). f. biol. Chem. 233, 5 .

Lee, O. S. \& Hart, W. A. (1944). Amer. F. Ophthal. 27, 488 .

Lerman, S. (I959). A.M.A. Arch. Ophthal. 6r, 88.

McLaren, D. S. (1960). Proc. Nutr. Soc. 19, 89.

Morton, R. A. (1944). Nature, Lond., 153, 69.

Noell, W. K. (1955). Amer. F. Ophthal. 40, no. 5, part 2, p. 60.

Oomen, H. A. P. C. (1958). Fed. Proc. 17, Suppl. no. 2, p. III.

Pirie, A. (1948-9). Brit. F. Nutr. 2, I4.

Rodger, F. C. (1960). Proc. Nutr. Soc. r9, 80.

Rushton, W. A. H. (1953). Acta physiol. scand. 29, 16.

Rushton, W. A. H. (1956). F. Physiol. 134, ir.

Rushton, W. A. H. (1958). Nature, Lond., 182, 690.

Schwarz, V. \& Golberg, L. (I955). Biochim. biophys. Acta, 18, 310.

Smelser, G. K. (1952). A.M.A. Arch. Ophthal. 47, 328.

Smelser, G. K. \& Chen, D. K. (1955). A.M.A. Arch. Ophthal. 53, 676.

Sydenstricker, V. P., Sebrell, W. H., Cleckley, H. M. \& Kruse, H. D. (1940). F. Amer. med. Ass. Ir4, 2437.

van Heyningen, R. (1959). Nature, Lond., 184, 194.

Wald, G. (1935). F. gen. Physiol. 19, 35x.

Wald, G. (1954). Science, rr9, 887 .

Wald, G., Brown, P. K. \& Smith, P. H. (1954-5). F. gen. Physiol. 38, 623 .

Wood, D. C., Massi, L. \& Solomon, E. L. (1959). 7. biol. Chem. 234, 329.

The following reviews, not mentioned in the text, contain further relevant information:

Dartnall, H. J. A. (1957). The Visual Pigments. London: Methuen.

Morton, R. A. \& Pitt, G. A. J. (1957). In Progress in the Chemistry of Organic Natural Products, 14, 245. (L. Zechmeister, editor.) Wien: Springet Verlag.

Pirie, A. \& van Heyningen, R. (1956). Biochemistry of the Eye. Oxford: Blackwell's Scientific Publications.

Wald, G. (1957). In Modern Problems of Ophthalmology, x, 173.

Wald, G. (1958). Science, 128, 1481 .

\title{
The crystalline lens in human and experimental malnutrition
}

\author{
By D. S. McLaren, East African Institute for Medical Research, Mwanza, \\ Tanganyika
}

Human cataract constitutes an outstanding problem from the point of view of aetiology, prevention and treatment amongst all races. It is assuming an increasingly important place, as congenital cataract remains in the hard core of little-understood congenital conditions, and as more and more people live long enough to develop senile cataract.

Several decades ago the discovery of such interesting facts as the very high concentrations of ascorbic acid, glutathione, and inositol in the normal lens, and the experimental production of lens changes in animals by diets deficient in riboflavin (Day, Langston \& O'Brien, I93I) or certain amino acids (Totter \& Day, I942; Hall, Bowles, Sydenstricker \& Schmidt, I 948) led only to false hopes that human cataract might be readily prevented by dietary means. Today the cataractous process interests biochemists, physiologists, electron microscopists and nuclear physicists, and nutritional aspects of the condition are being studied from fresh points of view. 